\title{
The role of screening, SIRS and qSOFA in Head and Neck Sepsis: An Audit of 104 Patients
}

\author{
Zain Sheikh¹, E Tian $\operatorname{Tan}^{1}$, Sunday Ifedayo ${ }^{2}$, and Quraishi M Shahed ${ }^{3}$ \\ ${ }^{1}$ Doncaster Royal Infirmary \\ ${ }^{2}$ West End Clinic \\ ${ }^{3}$ University of Sheffield Doncaster Royal Infirmary
}

November 16, 2020

\begin{abstract}
Key Points * Sepsis is associated with high morbidity and mortality and is a known complication of infections of the head and neck. Screening for sepsis should be conducted on admission in order to identify patients at risk and provide early intervention. * Our audit on an ENT ward in a district general hospital found that sepsis screening is poor, however this can be improved further by education and visual reminders such as poster or a clerking proforma. ${ }^{*}$ The most common head and neck infections admitted to a district general hospital were tonsillitis, peritonsillar cellulitis and peritonsillar abscesses. * The incidence of sepsis as a complication of head and neck infections is very rare if diagnosed according to the updated qSOFA criteria. * Using SIRS criteria may result in falsely high rates of diagnosis of sepsis and may lead to excessive and inappropriate clinical management in patients who could otherwise be managed less aggressively.
\end{abstract}

\section{Hosted file}

Full Paper anonymised.pdf available at https://authorea.com/users/376333/articles/493315-therole-of-screening-sirs-and-qsofa-in-head-and-neck-sepsis-an-audit-of-104-patients 


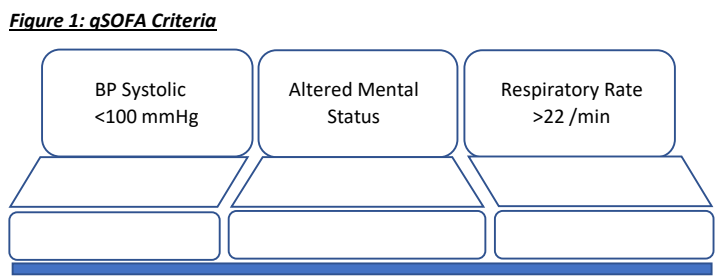



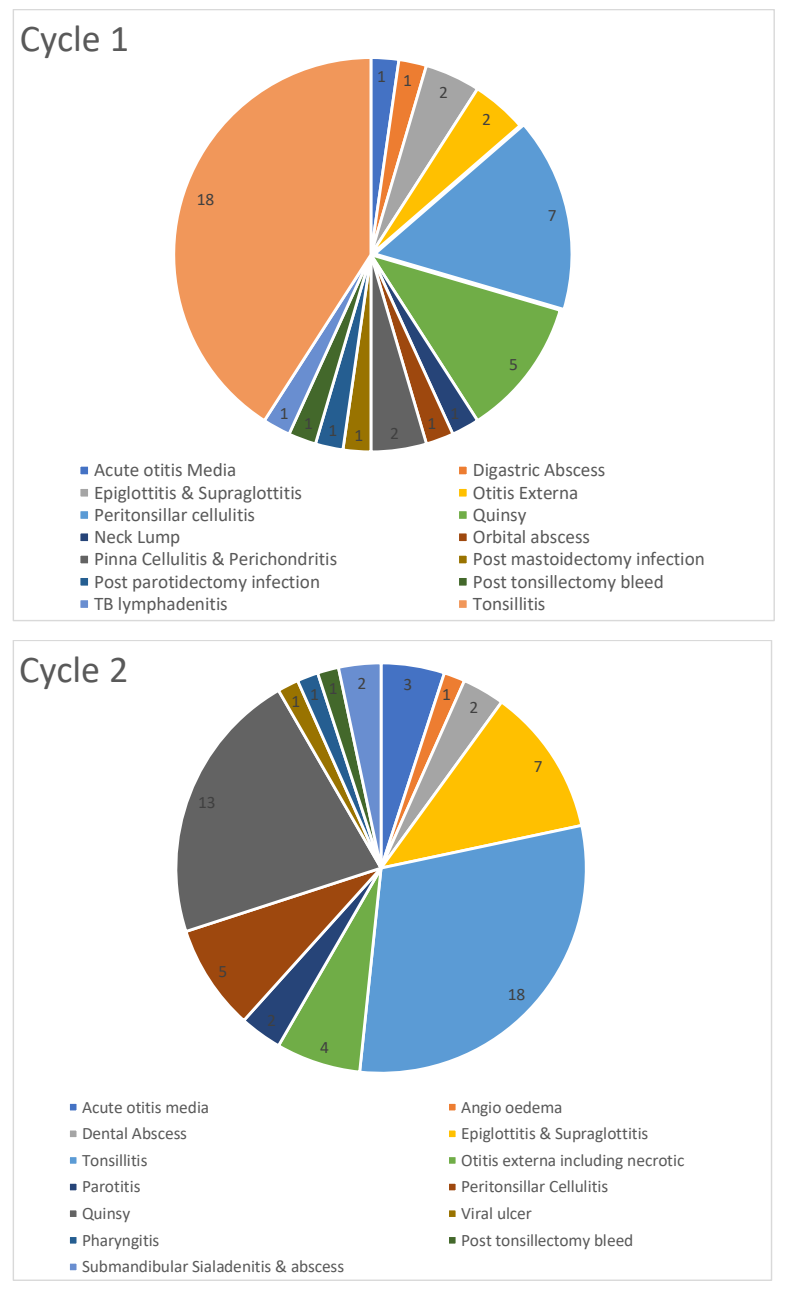

Figure 1: Frequency of Diagnoses of Cycle 1 and 2

\section{Hosted file}

Table 1 Comparison of SIRS and qSOFA.pdf available at https://authorea.com/users/376333/ articles/493315-the-role-of-screening-sirs-and-qsofa-in-head-and-neck-sepsis-an-auditof-104-patients

\section{Hosted file}

Table 2 Results of admissions.pdf available at https://authorea.com/users/376333/articles/ 493315-the-role-of-screening-sirs-and-qsofa-in-head-and-neck-sepsis-an-audit-of-104patients 